\title{
EL MONESTIR DE SANT PERE DE RODES EN ELS PROTOCOLS NOTARIALS DE CASTELLÓ D'EMPÚRIES DE 1279
}

\author{
MARIA JOSEPA ARNALL \\ Universitat de Barcelona
}

SUMARI

1. Descripció dels llibres.- 2. Els intruments. Apèndix.

Fins a les darreries del segle IX no tenim notícies escrites sobre l'existència de Sant Pere de Rodes. A partir d'aquest període s'esmenta com una simple cella monàstica depenent del monestir de Banyoles, i se n'independitzà l'any 944, malgrat que ja venia gaudint, de fet, d'una certa autonomia des d'alguns anys enrera. Abans de la meitat del segle X, la comunitat regida per Tassi (926-979) i el seu fill Hildesind (947-991), que fou el primer abat, començà a obtenir possessions fins $i$ tot en terres ben allunyades. Efectivament, els nombrosos dominis territorials reunits per l'abadia en el transcurs de l'esmentat segle s'estenien pels comtats d'Empúries, Peralada, Besalú, Girona, Barcelona, Osona, Pallars, Cerdanya, Fenollet, Vallespir i Rosselló. En força menys de mig segle, passà d'ésser una simple cel·la a convertir-se en un gran cenobi ${ }^{1}$.

El poder del centre monàstic es consolidà en les centúries següents, i durant el segle XIII arribà al seu màxim esplendor, éssent perfectament

\footnotetext{
'J. Badia I HomS, L'arquitectura medieval de l'Empordà. II-B Alt Empordà (Pont de Molins-Vilaür). Girona, Diputació Provincial, 1981, pp.47-144.

"Anuario de Estudios Medievales", 28 (1998)
} 
comparable al dels comtes d'Empúries. Una prova d'això la trobem en l'àmplia referència que d'aquest monestir apareix a les Rationes Decimarum Hispaniae $^{2}$, autèntic inventari que recull els censos de les esglésies i abadies confeccionats els anys 1279 i 1280 per recaptar la dècima o impost destinat al sosteniment de les Croades.

Aquesta mateixa preponderància va fer que Sant Pere de Rodes posseís, a l'igual que altres cenobis catalans, el privilegi de tenir els seus propis notaris que regien les escrivanies dels pobles senyorius del monestir. Els primers esments documentats d'aquestes escrivanies daten del segle XIII i foren concedides per establiment emfitèutic en els llocs on el cenobi tenia més propietats. Per exemple, destaquen a l'Empordà: Llançà ${ }^{3}$ (que incloïa també La Selva i la vall i muntanya de Sant Baldiri), Pedret, Marzà, Vilasacra, El Far, Fortià, Sant Joan Sescloses i Vilanova de la Muga, entre d'altres ${ }^{4}$. No obstant això, i atesa l'esmentada expansió monàstica, els monjos de Sant Pere de Rodes encomanaren la redacció d'una part de les seves escriptures a altres notaris, entre els quals es troben els de Castelló d'Empúries.

El fons notarial castelloní es custodia a l'Arxiu Històric de Girona ${ }^{5}$ i està integrat per més de 2100 volums que són una font excepcional per a l'estudi de la història, òbviament la social i econòmica de la vila de Castelló, del comtat d'Empúries i també d'una bona part de l'Empordà.

Castelló d'Empúries, per la seva condició de capital del comtat, aplegava gran nombre d'escrivents i juristes i esdevingué amb el temps una població burocràtica, com ho reflecteix la famosa dita popular recollida per Joan Amades: «Castelló Vila Major, tots són jutges i notaris».

La nombrosa documentació conservada, indubtablement, - però, no tota la produïda per haver-se dispersat i perdut en les múltiples vicissituds sofertes al pas del temps-, es deu a què els comtes tingueren la facultat privativa de nomenar els notaris del comtat. Per altra banda, com és sabut,

2 J. RiUS SERRA, Rationes Decimarum Hispaniae (1279-1280), Barcelona, 1946, I, pp. $65-$ 66 i $86-87$.

${ }^{3}$ M.T. Ferrer I MALLol, Llançà, senyoriu de Sant Pere de Rodes, en els segles XIV-XV, "II Col-loqui d'Història del Monaquisme Català" (Sant Joan de les Abadeses, 1970). Abadia de Poblet, 1974, pp. 213-242.

${ }^{4}$ M. J. ARnall I JuAn, Un manual de Sant Pere de Rodes del segle XVII ${ }^{\grave{ }}$. Estudi onomàstic $i$ notarial, "Annals de l'Institut d'Estudis Empordanesos", 18 (Figueres 1985), pp. 89-90.

${ }^{5}$ E. Mirambell i Belloc, Els protocols notarials històrics de Castelló d'Empúries, "Annals de l'Institut d'Estudis Empordanesos", 12 (Figueres 1977), pp. 215-246. 
existien a Castelló dues notaries propietat del comte. Ambdues tenien caràcter públic i eren conegudes pels noms vulgars d'En Bofill i d'En Mallén respectivament ${ }^{6}$.

Per tal d'esbrinar l'abast de la documentació rodesenca feta pels notaris castellonins, hem iniciat la nostra recerca començant amb el buidatge dels primers llibres notarials de Castelló que contenen assentaments referents a Sant Pere de Rodes.

Es tracta de dos manuals del notari Pere Serra redactats l'any 1279. Mentre en el primer llibre es comptabilitzen quatre documents de l'abadia de Rodes, en el segon el seu nombre s'incrementa a sis i a partir del tercer comencen a ser cada cop més nombrosos. Per aquest motiu, i considerant l'extensió limitada d'aquest treball, hem optat per donar a conèixer la documentació inserida en els dos primers llibres.

Respecte al perfil del notari Pere Serra, poques dades es coneixen. Pels llibres conservats - un total de tretze-, sabem que actuà a Castelló fins l'any 1299 i que desenvolupava el seu treball en qualitat de substitut en l'esmentada notaria d'En Mallén?.

\section{DESCRIPCIÓ DELS LLIBRES}

Els protocols notarials que enceten la sèrie de Castelló d'Empúries són llibres en paper ${ }^{8}$. En general, ambdós llibres tenen escassos marges i el

${ }^{6} \mathrm{M}$. Pujol I CANELles, Un inventari de la notaria d'En Bofill fins al primer terç del segle XVII a Castelló d'Empúries, "Annals de l'Institut d'Estudis Empordanesos", 21 (Figueres 1988), pp. 57-109.

${ }^{7}$ La vinculació de Pere Serra a la notaria d'En Mallén s'especifica concretament en el manual vuitè (a. 1294) i en el Llibre de Testaments d'aquest mateix notari (a. 1295), dades que, per altra banda, transmeten les primeres mencions conegudes de l'existència de la dita notaria a Castelló.

${ }^{8} \mathrm{El}$ que consta amb el número 1 comença així: Anno Domini millesimo ducentesimo septuagesimo nono, II' nonas iulii. Iste liber est intus Castilionis in tempore Petri de Serra, notarii publici Castilionis. Les seves dimensions són $310 \times 230 \mathrm{~mm}$. El conformen 40 folis numerats amb llapis, relligats amb pergamí. Les seves cares interiors s'han aprofitat per escriure-hi nombroses notes i dibuixos molt simples, com animals i signes notarials repetits a manera de prova.

El segon llibre s'enceta amb aquestes paraules. Liber communem (sic) et fuit inceptus kalendas aprilis, anno Domini millesimo ducentesimo septuagesimo nono, Petro de Serra notario publico Castilionis. Les seves dimensions són $300 \times 225 \mathrm{~mm}$. Consta de 50 folis numerats amb llapis, sense relligar. La manca d'enquadernació ha malmès els primers fulls. Aquests $\mathrm{i}$ altres de l'interior fins i tot s'han desprès dels fils de la relligadura. També el seu 
notari hi aprofita gairebé tot l'ample del foli, tal com era corrent en aquella època i s'observa en els manuals notarials coetanis.

Els assentaments són copiats amb escassa separació entre ells, de manera que, a vegades, en una sola plana s'hi troben enregistrats set instruments. Com a senyal que indica l'inici de cada un hi figura un traçat que simula un calderó.

L'escriptura emprada respon al cànon de la gòtica catalana en la seva condició de notular, la qual cosa li confereix una certa cursivitat en el seu traçat. És de mòdul petit, espessa, amb nombroses abreviatures, paraules afegides, esmenades i ratllades, que fan que el text doni la sensació de descurat.

En general, els assentaments es mostren amb molta concisió. Algunes frases - unes per formulàries $\mathrm{i}$ altres per clàusules molt conegudes-, es deixen sense desenvolupar com era força freqüent al segle XIII ${ }^{9}$. Sovint, amb una o dues paraules $\mathrm{i}$, en alguns casos, amb les primeres síl-labes seguides de punt i de l'abreviatura et cetera, s'inicien clàusules que, en l'instrument en pergamí, vindrien del tot explanades. Aquest és el cas, sobretot, de les clàusules renunciatives (renuncians, et cetera), corroborades amb jurament, o les d'obligació (obligo, et cetera; promitens, et cetera), on tot just s'insinua que els atorgants presenten garanties materials que obliguen la seva persona i béns per assegurar el cumpliment del pacte.

També ben sovint els noms patronímics venen expressats només per la seva lletra inicial i un punt que adverteix l'abreviació.

L'ordre cronològic en la inserció dels instruments és correcte, malgrat que no sempre s'assenyala l'esment de la datació. Tan sols quan canvia la data s'indica el mes i el dia segons la calendació romana, seguida de l'especificació concreta del dia de la setmana. Aquestes dades figuren ressaltades per dues línies a manera de requadre, el qual es troba a l'angle inferior-dret del final de l'assentament.

Val a dir que, de les deu nòtules que recollim a l'apèndix, vuit presenten constància dels barrats que denoten que els instruments respectius

\footnotetext{
estat de conservació no es tan bo com el llibre anterior, ja que s'observen uns quants folis deteriorats per la presència de solcs dels anaeròbics $i$, per altra banda, alguns assentaments són de difícil lectura degut a la tinta esvanida.

${ }^{9} \mathrm{~J}$. BONO, "Initia clausularum». La abreviación de cláusulas en el documento notarial, "Rvbrica. Paleographica et Diplomatica Studia", IV (Las abreviaturas en la enseñanza medieval y la transmisión del saber), (Barcelona 1990), pp. 75-96.
} 
s'han clos en pública forma, mentre dues d'elles - concretament la 3 i la 9no mostren cap indicació d'aquest tipus ni tampoc de cancel-lació o inutilització.

Per altra banda, en cap moment s'observen les sigles ct (clausum traditum), acreditatives d'haver-se lliurat als atorgants l'instrument posat en forma pública. Tampoc consten senyals especials, a base de ratlletes paral·leles inclinades sobre els patronímics dels interessats, que acreditin la conformitat de l'atorgament, costum molt freqüent en els llibres notarials coetanis d'altres contrades. Tanmateix, no hi ha indicis de què en alguna ocasió s'hagués fet jurament, cosa que era costum advertir damunt dels noms dels interessats amb els termes iuro, iuravit, iuraverunt.

En canvi, són bastant freqüents les anotacions que hi ha al marge esquerre referents al pagament o al deute de les taxes del notari, bé que sense la constància de xifres numèriques expressives de l'import. Tan sols les lletres $d$ de debet i $p$ de persolvit són les úniques que s'hi observen. És d'interès ressaltar també la presència, en algun cas al marge dret, de les lletres $\mathrm{ABC}$ que indiquen que es tracta de documents duplicats.

\section{ELS INTRUMENTS}

Els instruments rodesencs inserits en els manuals notarials de Castelló presenten una tipologia que respon plenament a la temàtica dels llibres coetanis d'aquestes característiques i al sistema feudal que configurà el règim social i polític durant l'època medieva ${ }^{10}$.

Els documents transcrits ens situen en una etapa de consolidació del domini monàstic, però el seu reduït nombre no permet fer una anàlisi valorativa de l'estructura econòmico-social d'aquest domini ni de la seva organització administrativa. Són ben pocs els instruments que contenen transaccions econòmiques importants fetes pel monestir. Els escassos exemples que reflecteixen aquesta mena d'operacions es concreten tan sols a dos. El primer conté una àpoca dimanada de la venda de les rendes del

\footnotetext{
${ }^{10}$ Aquesta temàtica és similar a la dels 17 documents originals del segle XIII (1221-1289), conservats a l'Arxiu de la Corona d'Aragó. Entre aquests es comptabilitzen: 2 compra-vendes, 3 definicions, 1 donació, 6 establiments emfitèutics, 1 permuta, 2 prestacions de vassallatge $\mathrm{i}$ 2 renúncies (V. F. SEvILlano Colom, Inventario de pergaminos medievales de monasterios gerundenses. Madrid, Dirección General de Archivos y Bibliotecas, 1953, I, pp. 187-205).
} 
castell de Vila-sacra, atorgada per l'abat Ramon a Joan Jaspert" ${ }^{11}$, que habitava en aquest lloc des del $1263^{12}$. Cal recordar que Vila-sacra va ésser una de les possessions més importants dels monjos de Rodes i, segons es té notícia, l'abril de 1240 el monestir comprà el castell i les seves jurisdiccions al noble Gilabert de Cruïlles ${ }^{13}$. A partir d'aquesta data són constants les adquisicions en aquest lloc fins a consolidar el seu domini al llarg del segle $\mathrm{XIV}^{14}$.

El segon exemple és la venda per quatre anys feta pel cambrer Pere de Corsavell a Ramon, clergue de la parròquia de Santa Maria de l'Estrada, de les rendes d'aquesta parròquia i de les de Santa Maria d'Agullana i de Sant Julià dels Torts ${ }^{15}$.

Entre els béns esmentats hi ha molins en diversos indrets i s'entreveu la distribució del terreny a base de propietats dividides en petites parcel·les destinades a conreu.

Com a mesura d'àrids emprada per als censos en espècie és citada l'aimina i els terminis dels pagaments són fixats per sant Feliu d'agost. Per altra banda, hom observa que també es realitzen pagaments en diners, predominant els sous melgoresos. Com és sabut, la moneda melgoresa, encunyada a l'antiga Magalona, -ciutat i seu episcopal de Septimània, primer pels comtes de Melguelh i després pels bisbes de MagalonaMontpeller-, circulava lliurement en temps del rei Jaume I (1213-1276), senyor de Montpeller, per tota aquesta zona de l'Empordà i també pels comtats de la Cerdanya, Rosselló i Vallespir. En general, en la documentació de Sant Pere de Rodes, el sou melgorès és la moneda per excel-lència que es troba present en totes les clàusules pecuniàries ${ }^{16}$, tot $i$ que en aquest indret circulaven a l'época medieval altres sistemes monetaris, com el sou

\footnotetext{
"Apèndix, doc. 4

${ }^{12}$ M. J. Arnall I Juan, Vila-sacra sota la influència de Sant Pere de Rodes (segles XIII$X V)$, "Annals de l'Institut d'Estudis Empordanesos", 17 (Figueres 1984), p. 122.

${ }^{13}$ Ibidem, p. 102.

${ }^{14}$ Ibidem, pp. 104-109.

${ }^{15}$ Apèndix doc. 10.

${ }^{16}$ M. J. ARnall i Juan, La moneda melgoresa en documentación de San Pedro de Rodes (siglos XIII-XIV), "XII ' Congrès d'Histoire de la Couronne d'Aragon" (Montpellier 1985), 2, pp. 33-45.
} 
barcelonès i el comtal emporità, aquest darrer documentat en una ocasió en l'apèndix que s'adjunta ${ }^{17}$.

Quant a les activitats dels individus que apareixen en aquesta documentació, en sabem poca cosa, ja que, tant en la relació dels atorgants com en la dels testimonis, no s'esmenten en cap moment els oficis que aquells exercien. L'única referència que els distingeix és l'al-lusió a la categoria eclesiàstica que acompanya, a vegades, el nom d'algun testimoni, tant si forma part de la comunitat de Sant Pere de Rodes com d'algun altre monestir o parròquia.

Davant de l'escassa documentació original conservada, en aquest breu treball dedicat a l'estimada Regina, hem volgut iniciar una línea de recerca que esperem que, en un termini no llunyà, pugui aportar noves dades a la història de Sant Pere de Rodes. El buidatge dels registres castellonins de ben segur que contribuirà en el coneixement d'un dels monestirs medievals més importants de casa nostra, que fins avui és enaltit només per les seves superbes restes monumentals.

\footnotetext{
${ }^{17}$ Apèndix, doc. 7.
} 


\section{APÈNDIX}

[1279] maig 5.

Berenguer de Palol, hostaler de Sant Pere de Rodes, declara deure a Ramon Morató de Fortià 50 sous melgoresos que li resten a pagar amb motiu de la compra d'un pollí de pèl vermellós. Actua de fiador Jaspert Riba de Castelló d'Empúries.

AHG, Castelló d’Empúries, manual 2, f. 15r.

Frater $^{1}$ Berengarius de Palaciolo, hostolerius ${ }^{2}$ monasterii Sancti Petri Rodensis, debeo tibi, Raimundo Moratoni de Furtiano, L solidos malgurienses qui tibi restant adhoc ${ }^{3}$ ad solvendum per $\mathrm{me}^{4}$ de precio cuiusdam pullini pilei baig quem a te $\mathrm{emi}^{5}$. Renuncio, et cetera, solvendo in festo sancti Felicis proxime, et dampno in omni super rebus predicte hostolerie ${ }^{6}$, et hoc iuro. Fideiussor: Iaspertus Rippa de Castilione, qui renuncio, et cetera, et obligo, et cetera.

III $^{\circ}$ nonas madii, die iovis.

Testes: Berengarius Rogerii, clericus, et P. Iohannis de Furtiano.

1. Al marge esquerre, persolvit.- 2. hostolerius corregeix hospitalerius.- 3. adhoc per adhuc.4. per me interlineat.- quem...emi interlineat.- 6 . super...hostolerie interlineat.

[1279 maig 18].

Arnau de Sexà, cambrer de Sant Pere de Rodes i procurador del monestir, concedeix al jutge Ramon una condomina de terra que l'abat Ramon li havia venut recentment, retenint-se, però, tot allò estipulat en els pactes o convenis que constaven en sengles instruments de compra-venda i de debitori. 
AHG, Castelló d'Empúries, manual 2, f. 17r.

Noverint ${ }^{1}$ universi quod die mercurii qua computabatur $\mathrm{XV}^{\circ}$ kalendas iunii, anno presenti, frater Arnaldus de Sexano, camerarius monasterii Sancti Petri Rodensis et procurator constitutus in hac parte, cum publico instrumento in hodierno kalendario confecto a domino fratre Raimundo, Dei gratia abbate iamdicti monasterii, in presencia et testimonio testium infrascriptorum, misit seu introduxit in possesionem corporalem Raimundum, iudicem, militem, de illa condomina terre quam dictus dominus abbas nuper dicto Raimundo vendidit cum publico instrumento, dando, videlicet, eidem Raimundo terram de ipsa condamina et tradendo manualiter intus dictam condaminam. De predictis tamen dictus frater Arnaldus ${ }^{2}$ excipit et retinuit, tam dicto domino abbati et suo conventu quam dicto Raimundo iudici et suis omnibus, convenciones ${ }^{3}$ inter eos habitas et retentas in dicto vendicionis instrumento et in quodam alio instrumento debitorio ${ }^{4}$ in hodierno kalendario confecto, ut in eisdem instrumentis ${ }^{5}$ continetur. Et de predictis predicti frater Arnaldus et Raimundus, iudex, mandaverunt mihi, Petro Pruni, scriptori iurato sub Petro de Serra, notario infrascripto, fieri publicum instrumentum $\mathrm{ad}^{6}$ inde habenda rei memoriam in eternum.

Quod fuit actum, et cetera.

Presentibus Guillelmo de Palacio, Guillelmo de Iaffero et Iuliano de Curtibus, clerico Sancte Crucis.

$\mathrm{BC}$

1. Al marge esquerre, persolvit.- 2. Arnaldus interlineat.-3. Segueix bus ratllat.- 4. debitorio interlineat.- 5. Segueix conden ratllat.- 6. Segueix dea ratllat.

3

[1279 maig 21].

Ramon, abat de Sant Pere de Rodes, absol Bernat Fort de la parròquia de Sant Esteve de Pedret contra tota petició i demanda fetes a ell $i$ als béns de Pere Fort, el seu fill difunt $i$ home propi del dit monestir, a causa del dret a la tercera part de tots els béns mobles que pertocava a l'esmentat cenobi per haver mort aquell ab intestato. A canvi el dit Bernat Fort pagà 50 sous melgoresos.

AHG, Castelló d'Empúries, manual 2, f. $17 v$. 
Frater $^{1}$ Raimundus, Dei gratia abbas monasterii Sancti Petri Rodensis, per nos et nostros successores in dicto monasterio, gratis, et cetera, solvo, diffinio penitusque remito tibi Bernardo Forti, parrochie Sancti Stephani de Petreto2, et tuis, perpetuo omnem accionem, questionem, peticionem et demandam, et cetera, quamcumque contra te et tuos et bona que condam fuerunt Petri Forti, filii tui condam, hominis nostri, facere, et cetera, ratione et occasione iuris nobis et dicto monasterio pertinenti, in tercia parte omnium bonorum mobilium que ${ }^{3}$ ipse habebat ratione quia decessit ab intestato. Ita quod nunquam, et cetera. Immo pactum, et cetera. Promitentes ratum, et cetera. Et inde L solidos malgurienses, renunciando, et cetera.

Testes: Frater Arnaldus de Sexano, camerarius dicti monasterii, et frater C., et Iacobus de Serra de Martsano.

1. Al marge esquerre, persolvit.- 2. Segueix fieri ratllat.- 3. Segueix nobis ratllat.

[1279] juliol 10.

L'abat Ramon de Sant Pere de Rodes confessa haver rebut de Joan Jaspert de Vilasacra 1000 sous melgoresos d'aquells 1100 que li debia de la venda per tot el present any de les rendes, collites, molins $i$ altres drets del castell de Vila-sacra, que li atorga per tot el dit any, excepte la llaurada que faci en terres de l'abadia.

AHG, Castelló d'Empúries, manual 2, f. 27r. i v.

Frater ${ }^{1}$ Raimundus, Dei gratia, abbas monasterii Sancti Petri Rodensis, per nos et nostros successores in dicto monasterio, profitemur et recognoscimus ${ }^{2}$ in veritate tibi, Iohanni Iauberti de Villasachre, tuisque, quod ${ }^{3}$ est per te nobis solutum et satisfactum de anno preterito in illis $\mathrm{MC}$ solidis malguriensibus ${ }^{5}$ in quibus nobis tenebaris ratione venditionis per nos tibi facte ${ }^{6}$ reddituum, proventuum et molendinorum ac laboracionum ${ }^{7}$ et aliorum omnium que nos recipimus et consuevimus ${ }^{8}$ recipere in toto castro de Villasachre et eius terminis. [... eti]am ${ }^{9}$ profitemur tibi quod $^{10}$ solvisti nobis et recepimus a te pro presenti anno $\mathrm{M}$ solidos malgurienses, renunciando peccunie non numerate, et cetera ${ }^{11}$. Unde de predictis absolvimus, et cetera, et facimus pactum, et cetera. Preterea volumus et concedimus tibi quod sit tibi, salva laboracione ${ }^{12}$ quam feceris ${ }^{13}$ in terris nostris dicti loci, per totum presentem annum ad usum laboratoris.

$\mathrm{VI}^{\mathrm{o}}$ idus iulii, die dominica. 
Testes: Poncius Taboni, iurisperitus, Iulianus de Curtibus et Matheus Marceti.

1. Al marge esquerre, persolvit.- 2. Després de la sil-laba nos segueix sus ratllat.- 3. Segueix de ratllat.- 4. Segueix de omnium hoc ratllat.- 5. in illis MC solidis malguriensibus corregeix de omnium hoc.- 6. venditionis...facte interlineat.- 7. proventuum...laboracionum interlineat.- 8. consue corregeix conue. - 9. Espai de deu lletres aprox. il-legible degut a la mutilació del paper.- 10. Segueix do ratllat.11. peccunie...et cetera interlineat. A continuació segueix una línea ratlada.- 12. Segueix ad ratllat.- 13. Segueix ad ratllat.

[1279] agost 11.

Bernat de Garriga, cellerer de Sant Pere de Rodes, confirma a Alamanda, filla d'A. Serra de Garriguella, un camp situat a la parròquia de Sant Joan Sescloses que té sota el domini directe del monestir, a cens d'una aimina d'ordi pagadora per sant Feliu, a raó de la tasca, braçatge i demés agraris que acostumava fer, i de 34 sous melgoresos rendals.

AHC, Castelló d'Empúries, manual 1, f. 13r.

Frater ${ }^{1}$ Bernardus de Garrica, cellerarius monasterii Sancti Petri Rodensis, gratis, per me et meos successores, laudo ${ }^{2}$ et concedo et imperpetuum confirmo tibi, Alamande, filie A. Serre de Garrigella, et tuis, quendam campum tuum terre quem habes et tenes per me in parrochia Sancti Iohannis de Crosis apud Gormanyno, ab oriente in carraria publica, ab occidente in terra Iacobi Orger et Godaylli, a meridie in terra Caylaboci, a circio in terra Rexachi et Raimundi Porcelli. Ita ut habeas ad voluntatem, salvo iure et dominio meo et meorum successorum, et dabis me tu et tui semper mihi et meis annuatim de censu unam eyminam ordei boni, et cetera, sancto Felice ad migeriam censualem ratione tasque et braciatici et omnium aliorum agrariorum que me dare solebas, ablatam cum tuis tuorumque sumptibus in quocumque loco. Ego et mei successores volumus, et cetera, intus villam Castilionis $^{3}$. Promitens, et cetera, me XXXIIII solidos malgurienses rendales.

Testes: P. A. de Stagneolo ${ }^{4}$ et Matheus Marceti de Sancta Cruce.

III idus augusti, die veneris.

1. Al marge esquerre, persolvit.- 2. Segueix mus ratllat.- 3. ablatam...Castilionis interlineat.4. de Stagneolo interlineat. 
[1279 agost 21].

Bernat, clergue de Fortià i domer de Castellò d'Empúries, restitueix a Ramon, abat de Sant Pere de Rodes, l'exercici de la justícia i el coneixement de les causes que el dit abat i el seu predecessor li van atorgar sobre tota la muntanya de Sant Pere, la parròquia de Llançà, Vilajuïga, Palausaverdera, Roses i Cadaqués. Es reté, però, les causes de les apel-lacions cedides a Julià de Corts, sempre i quan no morís abans que ell.

AHG, Castelló d'Empúries, manual 1, f. $15 \mathrm{v}$.

Bernardus $^{1}$, clericus de Furtiano, ebdomedarius ecclesie ${ }^{2}$ Castilionis $^{3}$, dono, diffinio et remito vobis domino fratri Raimundo, Dei gratia abbati monasterii Sancti Petri Rodensis, et conventui vestro, illam gratiam de iudicatu et cognicione omnium causarum, quam michi vos et predecessor vestri fecerunt de tota montanea Sancti Petri et de parrochia de Lanciano et de Villaiudayca et de Palacio de Viridaria et de Rosis et de Cadacheriis, tam rerum quam personarum. Ita quod de cetero in predictis nichil exigam de ratione ${ }^{4}$. Hoc autem facio, salvo et retineo causas appelacionum predictorum locorum de quibus Iulianus de Curtibus cognovisset in principali causa, et salvo etiam hoc quod si contingeret dictum Iulianum mori antequam $\mathrm{me}^{5}$ teneam recuperare ${ }^{6}$ predictum iudicatum de omni vita mea $^{7}$.

Testes: Frater A., porterius Sancti Petri, et frater P. de Sancto Iohanne et Guillelmus Letonus.

1. Al marge esquerre, debet.- 2. ecclesie interlineat.- 3. Segueix s ratllada.- 4. de ratione interlineat.- 5. me corregeix quod.- 6. Segueix predicta de omni vita mea ratllat.- 7. salvo etiam...vita mea interlineat.

[1279 agost 21].

Julià de Corts, clergue de Santa Creu, concedeix de forma vitalícia a Bernat, clergue de Fortià, les rendes i els ingressos de la capellania de l'església de Sant Joan Sescloses que l'abat de Sant Pere de Rodes li havia cedit, a causa d'haver-li atorgat dit abat al mateix Julià l'exempció de ser jutge $i$ 
d'examinar les causes. Es reté, però, la concessió dels beneficis de la dita església. Per altra banda, el dit Bernat es compromet a donar-li 22 sous comtals que rep anualment en nom de l'esmentat abat del lloc de l'Estanyol, concretament, 11 sous del mas de Guerau Nicolau i altres 11 del mas de Pere Arnau.

AHG, Castelló d'Empúries, manual 1, f. $15 \mathrm{v}$.

Iulianus $^{1}$ de Curtibus, clericus Sancte Crucis, dono vobis Bernardo, clerico de Furtiano, de omni vita vestra omnes redditus, proventus et exitus capellanie ecclesie Sancti Iohanni de Crosis, retento mihi collacione beneficiorum ipsius ecclesie, et hoc facio propterea ${ }^{2}$ quia placuit vobis michi facere gratiam et dimitere iudicatum et cognicionem causarum amore $^{3}$ et gratia mei, de quo dominus abbas Sancti Petri Rodensis providit michi. Et convenio vobis quod predictos redditus, exitus et proventus dicte capellanie faciam vobis habere et accipere ac colligere in pace de omni vita vestra. Et ego, dictus Bernardus, clericus, dono et remito tibi, Iuliano, de omni vita mea, illos XXII solidos comitales quos ego recipio nomine dicti domni abbatis apud Stagneolum annuatim, scilicet, in manso Geraldi Nicholai ${ }^{4}$, XI solidos comitales ${ }^{5}$, et in manso Petri Arnaldi, alios XI solidos comitales ${ }^{6}$. Promitens quod faciam habere, et cetera, de omni vita mea.

Testes: idem.

$\mathrm{ABC}$

1. Al marge esquerre, debet.- 2.- Després de propter segueix hec ratllat.- 3. amore corregeix amorum.- 4. Nicholai interlineat.- 5. comitales corregeix malgurienses.- 6. comitales corregeix malgurienses.

[1279] setembre 21 .

L'abat Ramon de Sant Pere de Rodes enfranqueix Ermessenda, dona pròpia de Vilafant, filla del difunt Bernat Seguer, pel preu de 2 sous melgoresos.

AHG, Castelló d’Empúries, manual 2, f. 44r.

Frater $^{1}$ Raimundus, Dei gratia abbas monasterii Sancti Petri Rodensis, gratis, et cetera, per nos et nostros successores, diffinimus et ab omni dominio et servitute mea et successorum meorum eicimus Ermesendam, filiam condam Bernardi Segerii ${ }^{2}$, feminam nostram de Villafedando ${ }^{3}$, et omnia bona sua, licet absentem tanquam presentem, in posse tui, notarii infrascripti, nomine eius stipulanti et 
recipienti, imperpetuum ${ }^{4}$. Ita quod nunquam in ea nec in prole ab ipsa nascitura, $e t$ cetera. Immo sic, et cetera, faciendo pactum, et cetera. Predictam siquidem diffinitionem facimus sibi $[\ldots]^{5}$ et in manu et posse cuiuscumque domini facere et eligere volueris ad eius voluntates. Et sic promitimus, et cetera, in racione, et cetera, et unde II solidos malgurienses, renunciando, et cetera.

XI kalendas octobris, die mercurii, festum Sancti Mathey.

Testes: Bernardus de Mora, baiulus de Marziano, et C. Textor de Faro.

1. Al marge esquerre, persolvit.- 2. Segueix ds ratllat.- 3. Segueix et ora ratllat.- 4. imperpetuum interlineat.- 5. Espai de sis lletres aprox. il-legible degut a una raspadura.

[1279 octubre 4].

L'abat Ramon de Sant Pere de Rodes reconeix haver rebut de Bernat d'Estany d'El Far, en dos pagaments, un total de 150 sous melgoresos d'aquells 750 sous que li devia pels danys causats al monestir $i$ als molins que aquest té a El Far.

AHG, Castelló d’Empúries, manual 2, f. 49r.

Frater ${ }^{1}$ Raimundus, Dei gratia abbas monasterii Sancti Petri Rodensis, per nos et nostros successores in dicto monasterio, profitemur et recognoscimus in veritatem tibi, Bernardo de Stagno de Faro, tuisque, quod solvisti nobis, et nos a te recipimus voluntatis nostre, illos LXXV solidos malgurienses quos nobis solvere debebas in festo Sancte Marie septembris proximo preterito, et alios LXXV solidos malgurienses quos nobis similiter debebas solvere in festo preterito Sancti Michaelis, de illo debitorio DCCL solidos malgurienses quos nobis debes ${ }^{2}$ cum instrumento quod penes nos habemus, confecto $I^{\circ}$ kalendas iulii anno presenti, ratione dampnorum datorum nobis et molendinis ${ }^{3}$ nostris de Faro per te et filiam tuam, prout in dicto debitorii instrumento continetur. Renunciando, et cetera. Unde ${ }^{4}$ gratis, et cetera, de dictis ${ }^{5}$ denariis, qui sic sunt $\mathrm{CL}$ solidi malgurienses, te et tuos absolvo, et cetera, et pactum, et cetera.

Testes: Guillelmus Ferrarii de Faro, frater A. de Sexano, camerarius dicti monasterii.

1. Al marge esquerre, debet.- 2. debes corregeix debebas.- 3. Segueix ts ratlat.- 4. Segueix un espai de quatre lletres aprox. ratllat.- 5. Segueix omnibus ratllat. 
[1279 octubre 24]

Pere de Corsavell, cambrer del monestir de Sant Pere de Rodes, ven a Ramon, clergue de Santa Maria de l'Estrada, des del primer de juny i per quatre anys, totes les rendes $i$ els ingressos de les parròquies de Santa Maria de l'Estrada, de Santa Maria d'Agullana i de Sant Julià dels Torts, excepte la meitat dels foriscapis i dels lluismes, pel preu de 12 sous melgoresos anuals pagadors per Nadal.

AHG, Castelló d’Empúries, manual 1, f. 40r

Frater Poncius de Cursavello, camerarius monasterii Sancti Petri Rodensis, per me et omnes succesores meos ${ }^{1}$, vendo tibi, Raimundo, clerico Sancte Marie de Strada, et tuis, et cui volueris, de kalendis mensis iunii proximi preteriti ad IIII annos continue completos, omnes redditus et proventus, census, agraria et obvenciones que habeo et accipio et habere accipere, debeo et consuevi in tota parrochia Sancte Marie de Strada et Sancte Marie de Aguylana et Sancti Iuliani de Tortis. Hoc autem salvo mihi medietatem omnium foriscapium et laudismorum, precio quolibet anno XII solidos malgurienses, de quos ${ }^{2}$ mihi pacaturus sic, scilicet, quolibet anno in festo sancti ${ }^{3}$ Natalis Domini XII solidos malgurienses. Et sic de predictis mito te, et cetera. Ita ut habeas, et cetera. Et si plus, et cetera, remito et convenio quod non tangam, sed faciam habere et in omni. Et ego R., clericus predictus, laudo et convenio in omni et iuro.

Testes: R. de Lercio et Iohannes Goba de Castilionis.

$\mathrm{ABC}$ Fe ratllat.

1. Segueix $\mathrm{m}$ ratllada.- 2. quos per quibus.- 3. sancti sense cancel-lar $i$ a continuació segueix

\section{RÉSUMÉ}

Sant Pere de Rodes fût l'un des monastères les plus anciens de Catalogne, mais on ne dispose pas d'informations écrites à son sujet avant la fin du IXème siècle. Ses ruines monumentales indiquent qu'il s'agissait d'une abbaye importante, mais la dispersion ou la perte de ses archives et les rares documents d'origine conservés ne permettent pas de 
connaitre les détails de son histoire. Afin de remédier à une telle carence, cet article se propose d'amorcer une ligne de recherches fondée sur le dépouillement des protocoles notariaux de Castelló d'Empúries dont les notaires étaient fréquemment mis à contribution par les moines de Rodes pour rédiger leurs écrits. Nous donnons à connaître les premiers résultats obtenus dans l'appendice constitué de dix documents inserrés dans les deux premiers registres de Castelló, datant de 1279.

\section{SUMMARY}

Sant Pere de Rodes has been one of the most ancient monasteries of Catalonia but no written information is available about it until the end of the ninth century. Its monumental ruins show that it used to be an important abbey, but the scattering or loss of its archives and the very few original documents which have been kept do not allow us to learn about the details of its history. In order to remedy such a deficiency the purpose of this article is to start a new line of investigation by exhausting the notarial protocols of Castelló d'Empúries, where the monks of Rodes used to visit frequently the notarial offices in order to have their writings drawn up. Information about our first findings is included in the appendix consisting of ten documents which are inserted in the first two registers of Castelló, dated 1279. 